\title{
Comparison of pregnancy outcome between clomiphene citrate and sequential clomiphene citrate+human menopausal gonadotropin in intrauterine insemination
}

\author{
Ankita Singh ${ }^{1 *}$, Rohan Palshetkar ${ }^{1}$, Namrata Singh ${ }^{2}$, Awyay Rege ${ }^{3}$
}

\author{
${ }^{1}$ Department of Obstetrics and Gynecology, D. Y. Patil Hospital, Nerul, Navi Mumbai, Maharashtra, India \\ ${ }^{2}$ Intern, Sri Aurobindo Medical College and PG Institute, Indore, Madhya Pradesh, India \\ ${ }^{3}$ Department of Orthopedics, Lilavati Hospital, Bandra West, Mumbai, Maharashtra, India
}

Received: 28 May 2020

Accepted: 03 July 2020

\section{*Correspondence:}

Dr. Ankita Singh,

E-mail: dr.ankitasinghh@gmail.com

Copyright: (C) the author(s), publisher and licensee Medip Academy. This is an open-access article distributed under the terms of the Creative Commons Attribution Non-Commercial License, which permits unrestricted non-commercial use, distribution, and reproduction in any medium, provided the original work is properly cited.

\begin{abstract}
Background: Intrauterine insemination (IUI) has been widely used as a common treatment for infertile couples. This study compares the sequential clomiphene citrate (CC) treatment with $\mathrm{CC}$ and human menopausal gonadotropin (hMG) treatment in women undergoing IUI. Therefore, this study was designed to determine the effects of addition of gonadotropin $(\mathrm{CC}+\mathrm{hMG})$ would improve the pregnancy rate in women undergoing IUI. And also compare the sequential $\mathrm{CC}+\mathrm{hMG}$ treatment with $\mathrm{CC}$ treatment in women undergoing IUI.

Methods: A cross-sectional study design was conducted at D. Y. Patil Fertility Centre, D.Y Patil Hospital, Navi Mumbai from September 2018 to August 2019. Source populations were all patients who live in Mumbai, Maharashtra, India. A total of 67 patients were enrolled in this study. (It consisted of 67 sub fertile couples undergoing ovarian stimulation for IUI cycles).

Results: There was no significant difference between the two studied groups regarding endometrial thickness $(8.3 \pm 2.1$ versus $9.7 \pm 2.8$, respectively), number of mature follicles on the day of hCG injection $(3.3 \pm 1.2$ versus $3.5 \pm 1.1$, respectively) and, but there was significant difference between the $\mathrm{CC}+\mathrm{hMG}$ group and $\mathrm{CC}$ group regarding the total dose of gonadotropins used in ovulation induction $(305 \pm 23.8$ versus $655 \pm 192$; total IU, respectively) $\mathrm{p}<0.05$. Conclusions: Women undergoing IUI, ovarian stimulation CC combined with hMG, significantly improved the pregnancy and live birth rates as compared to that of CC group. In women undergoing ovarian stimulation and IUI, there are no significant differences in pregnancy and live birth rates among the various stimulation protocols.
\end{abstract}

Keywords: Clomiphene citrate, Human menopausal gonadotropin, Intrauterine insemination

\section{INTRODUCTION}

Intrauterine Insemination (IUI) has been widely used as a common treatment for infertile couples. The reported clinical pregnancy rate varies considerably, ranging from 5 to $20 \% .^{1-4}$ IUI technique is widely used to treat infertile couples with mild male factor infertility, anovulation, endometriosis, unexplained infertility, and other infertility causes, the limited IUI success rate can be affected by several factors with little consensus. ${ }^{5-8,9}$ The potential beneficial effect of human menopausal gonadotropin (hMG) IUI cycles are associated with an increased rate of pregnancy clinically. Among them, the female's age, the male's sperm quality, the IUI attempt rank, the infertility type, and the used gonadotropin for controlled ovarian stimulation (COS) are considered the most predictive factors of IUI clinical outcomes. ${ }^{10-16}$ Despite its widespread use, the role and type of COS combined with IUI is controversial. Clomiphene citrate, an anti-estrogen, is mostly used as first choice for COS in 
the context of IUI since clomiphene can be administered orally and is cheaper than gonadotrophin injections. ${ }^{17-19}$ IUI is considered a first-line procedure among assisted reproductive techniques due to its simplicity, ease of management, relatively low incidence of complications and low cost. Nevertheless, when IUI is used, should ovarian stimulation be used at the same time. Some investigator shave advocated using the natural cycle..$^{20,21}$ The IUI method is less expensive and less complicated compared with the other assisted reproductive technology, the in vitro fertilization (IVF) protocol. Since six clinical factors the female-age, endometrial thickness (ET), luteinizing hormone (LH), number and size (mm) of ovary follicles, and male factor, i.e., total motile fraction (million) controlled the success rate of an IUI protocol, it was intuitive to study the role of individual factors in the success. The sequential Clomiphene Citrate (CC) with hMG treatment improves response to $\mathrm{CC}$, decreases hMG dose and finally reduces the treatment cost. During the sequential CC with hMG treatment, CC ( $100 \mathrm{mg} /$ day) is started for 5 days, followed by hMG 75 IU for 4 days. ${ }^{22,23}$ Sequential CC With hMG treatment appears to be a cost-effective method in ovulation induction, requires less monitoring and leads to satisfactory pregnancy results. ${ }^{24}$ Therefore, this study was designed to determine the effects of addition of gonadotropin $(\mathrm{CC}+\mathrm{hMG})$ would improve the pregnancy rate in women undergoing IUI. And also compare the sequential $\mathrm{CC}+\mathrm{hMG}$ treatment with $\mathrm{CC}$ treatment in women undergoing IUI.

\section{METHODS}

A cross-sectional study design was conducted at D. Y. Patil Fertility Centre, D. Y. Patil Hospital, Navi Mumbai from September 2018 to August 2019. Source populations were all patients who live in Mumbai. A total of 67 patients were enrolled in this study. (It consisted of 67 sub fertile couples undergoing ovarian stimulation for IUI cycles.) All the recruited patients were explained about the study and written consent was taken from every patient dually signed by her.

Ethical approval and clearance were taken from institutional review of College of D. Y. Patil Fertility Centre and permission letter for data and sample collection has also been received from the department of obstetrics and gynecology. The cases were divided into two groups. The first group is the gonadotropin group (CC+hMG) (32 patients) and the second control (CC) (35 patients).

\section{Inclusion criteria}

- Women of good physical and mental health, 18-37 years old, with regular menstrual cycles, of 25-35 days, primary or secondary infertility for more than one-year, body mass index (BMI) less than $30 \mathrm{~kg} / \mathrm{m}^{2}$, no patient had received any hormone therapy for at least 60 days preceding the study. Normal prolactin levels, normal thyroid function, normal uterine cavity and bilateral tubal patency assessed by hysterosalpingography and/or laparoscopy.

\section{Exclusion criteria}

- Women with hormone values outside the reference range by day 3-4 of their menstrual period (FSH levels $>10 \mathrm{mIU} / \mathrm{l}$ ) and with polycystic ovarian syndrome were excluded from this study.

Moreover, only patients with partners with normal seminal parameters according to World Health Organization (WHO) criteria and whose total motile sperm count (TMSC) after sperm washing by swim-up was equal to or greater than $10 \mathrm{million} / \mathrm{ml}$ were accepted.

\section{Hormonal treatment}

\section{Gonadotropin group (CC+hMG)}

A total 32 patients were subjected to a controlled ovarian stimulation (COS) protocol in which the use of CC with hMG IUI is associated with an increased rate of pregnancy (RP) clinically. On the 2 day of their menstrual period, the patients were examined by ultrasound to ensure ovarian quiescence. A fixed dose of $100 \mathrm{mg} /$ per day of CC was then given to induce follicle recruitment for 5 days. At day 7 of COS, an ultrasound was performed to start injection hMG 75 IU and adjust the dose accordingly thereafter, if necessary. Subsequently, follicular development was monitored by ultrasound every 1 or 2 days. When adequate ovarian response was observed (follicles $=18 \mathrm{~mm}$ ), $10000 \mathrm{IU} / \mathrm{i} . \mathrm{m}$. hCG was administered, IUI was performed 36 hours later. IUI was cancelled if more than four follicles $(16-20 \mathrm{~mm})$ were present, in order to reduce the risk of multiple pregnancy. No severe ovarian hyperstimulation syndrome occurred. One cycle was converted to an IVF cycle due to excessive ovarian response (eight follicles $\geq 18 \mathrm{~mm}$ ).

\section{Control group $(C C)$}

Total 35 patients were subjected, the hMG was not used and $\mathrm{CC}$ was administered from day 2 of menstrual cycle for 5 days. The dose was $100 \mathrm{mg}$ once a day. Ultrasound was done every 1 or 2 days. When leading follicle reached $\geq 18 \mathrm{~mm}$, hCG was given and IUI was performed $36 \mathrm{hrs}$ later. As in the other group, IUI was cancelled if more than four follicles $(16-20 \mathrm{~mm})$ were present. One cycle was cancelled in order to avoid a multiple pregnancy since ultrasound had revealed seven follicles $\geq 18 \mathrm{~mm}$.

\section{Semen preparation}

Semen analysis was collected after 2-3 days of abstinence. Concentration (number of sperm present per $\mathrm{ml}$ of the ejaculate): greater than $15 \mathrm{million} / \mathrm{ml}$ motility (percentage of sperm moving): $50 \%$ or more. It should 
take 10 to 20 minutes before semen liquefies. While semen is initially thick, its ability to liquefy, or turn to a watery consistency, helps sperm to move. If semen does not liquefy in 10 to 20 minutes, fertility could be affected. The semen was incubated for 30 minutes at $37^{\circ} \mathrm{C}$, and after liquefaction, the volume and viscosity were determined. The motility and initial concentration of the spermatozoa were calculated using a makler chamber. Swim-up technique was used to prepare the semen. Sperm preparation medium (60 ML; Medicult R) was used to wash the semen. The samples were incubated at $37^{\circ} \mathrm{C}$ in $5 \% \mathrm{CO}_{2}$ for 45 minutes on an inclined rack using the same culture medium. Finally, the concentration of motile spermatozoa in the preparation was determined using the makler chamber.

\section{IUI procedure}

The procedure itself involves transferring specially washed semen directly into the uterus via a thin catheter. Only single IUI was done at $36 \mathrm{~h}$ after Human chorionic gonadotropin (hCG) injection and the day of the IUI was recorded. $\beta$-hCG levels were measured on cycle day 22. If ovarian hyper stimulation syndrome (OHSS) developed, it was recorded and classified as mild, moderate or severe based on the combination of ovarian enlargement and the acute shift of the fluid to the extra vascular space. A diagnosis of clinical pregnancy was confirmed by serum $\beta$-hCG concentration and visualization of the gestational sac on subsequent ultrasound examination. The primary outcome measures were the pregnancy rate, number of mature follicles and total dose of gonadotropins used in ovulation induction, while the secondary outcome measures were the number of cases that developed ovarian cyst and number of cases that developed OHSS after ovulation induction.

\section{Statistical analysis}

Data were expressed as the mean \pm SD. Continuous variables were compared with Student's t-test. The Chisquare test and Fisher test were used to compare clinical outcome between the two groups. The analysis was carried out using the statistical package for social sciences SPSS-20 (IBM). The $\mathrm{p}=0.05$ was considered significant.

\section{RESULTS}

Total 67 patients were included in the study and were equally divided into two groups: one with gonadotropins (CC+hMG) and the other is the control (CC) group. There are no statistically significant differences between the two groups regarding age and BMI. There were also no statistically significant differences between the two groups in terms of duration of infertility (Table 1). In Table 1, were noted between the CC+hMG treated group and the control group. There was no significant difference between the two studied groups regarding endometrial thickness $(8.3 \pm 2.1$ versus $9.7 \pm 2.8$, respectively), number of mature follicles on the day of hCG injection (3.3 \pm 1.2 versus $3.5 \pm 1.1$, respectively) and, but there was significant difference between the $\mathrm{CC}+\mathrm{hMG}$ group and $\mathrm{CC}$ group regarding the total dose of gonadotropins used in ovulation induction $(305 \pm 23.8$ versus $655 \pm 192$; total IU, respectively) $\mathrm{p}<0.05$; Table 2 ).

Table 1: Ovulation for intrauterine insemination gonadotropins.

\begin{tabular}{|c|c|c|c|}
\hline & CC+hMG Group (n=32) & CC Group (n=35) & p-value $\left(X^{2}\right)$ \\
\hline Age (years) & $33.7 \pm 2.5$ & $31.02 \pm 3.1$ & $0.83(\mathrm{NS})$ \\
\hline $\operatorname{BMI}\left(\mathrm{kg} / \mathrm{m}^{2}\right)$ & $23.7 \pm 2.7$ & $22.3 \pm 2.6$ & $0.87(\mathrm{NS})$ \\
\hline \multicolumn{4}{|c|}{ Main causes of infertility (n) } \\
\hline Unknown & $23(71.8 \%)$ & $20(57.1 \%)$ & \multirow{2}{*}{$0.20(\mathrm{NS})$} \\
\hline Anovulation parity & $9(28.1 \%)$ & $15(42.9 \%)$ & \\
\hline \multicolumn{4}{|l|}{ Parity (n) } \\
\hline Primary infertility & $28(87.5 \%)$ & $32(91.4 \%)$ & \multirow{2}{*}{$0.59(\mathrm{NS})$} \\
\hline Secondary infertility & $4(12.5 \%)$ & $3(8.6 \%)$ & \\
\hline
\end{tabular}

CC: Clomiphene citrate, hMG: Human menopausal gonadotropins, BMI: Body mass index, *Values are (m \pm sd); NS: Not significant; $\mathrm{X}^{2}$ : Chi square.

As expected, cycle length was extended to almost 1 day more $(7.5 \pm 1.7$ versus $6.5 \pm 1.6$; days) in the $\mathrm{CC}+\mathrm{hMG}$ treated group than in the control group, although this difference was not statistically significant. In CC+hMG group and in $\mathrm{CC}$ control group were the cases with of singletons and multiple $[12(85.7 \%)$ versus $8(100 \%)$ and $1(7.1 \%)$ versus $0(0 \%)$, respectively], but the pregnancy rate was significantly high in the $\mathrm{CC}+\mathrm{hMG}$ group compared to the CC group [14 (43.7\%) versus 9 (25.7\%), respectively] $(\mathrm{p}<0.05$; Table 3$)$.
There have been no miscarriages in both groups. Pregnancy rates were significantly increased in the group of patients receiving the gonadotropin (hMG) $(43.7 \%)$ compared to the control group (25.7\%). And number of cases with of singletons and multiple [12 $(85.7 \%)$ versus $8(100 \%)$ and $1(7.1 \%)$ versus $0(0 \%)$, respectively, to date, except for one ectopic pregnancy $7.1 \%$ in the $\mathrm{CC}+\mathrm{hMG}$ and $11.1 \%$. in CC group. There have been no miscarriages and no live births occurred in the both groups (Table 3). 
Table 2: Timing ovulation for intrauterine insemination with a gonadotropin.

\begin{tabular}{|llll|}
\hline & CC+hMG Group $(\mathbf{n}=\mathbf{3 2})$ & CC Group $(\mathbf{n}=\mathbf{3 5})$ & $\mathbf{p}$-value $\left(\boldsymbol{X}^{\mathbf{2}}\right)$ \\
\hline Day of IUI & $14.7 \pm 0.5$ & $13.5 \pm 0.7$ & $0.86(\mathrm{NS})$ \\
\hline Gonadotropins (total U) & $305 \pm 23.8$ & $655 \pm 192$ & $<0.05(\mathrm{~S})$ \\
\hline Stimulation (days) & $7.5 \pm 1.7$ & $6.5 \pm 1.6$ & $0.52(\mathrm{NS})$ \\
\hline Follicles $(\geq 18 \mathrm{~mm})$ on the day of hCG injection & $3.3 \pm 1.2$ & $3.5 \pm 1.1$ & $0.84(\mathrm{NS})$ \\
\hline Swim-up sperm $\left(\times 10^{6} / \mathrm{ml}\right)$ & $22.9 \pm 9.0$ & $19.7 \pm 18.2$ & $0.75(\mathrm{NS})$ \\
\hline Endometrial thickness $(\mathrm{mm})$ & $8.3 \pm 2.1$ & $9.7 \pm 2.8$ & $0.88(\mathrm{NS})$ \\
\hline
\end{tabular}

CC: Clomiphene citrate, hMG: Human menopausal gonadotropins, IUI: Intrauterine insemination, hCG: Human chorionic gonadotropin, *Values are (mean \pm sd), NS: Not significant; $X^{2}$ : Chi square.

Table 3: Timing ovulation for intrauterine insemination with a gonadotropin.

\begin{tabular}{|llll|}
\hline & CC+hMG Group $(\mathbf{n = 3 2})$ & CC Group $(\mathbf{n = 3 5})$ & p-value $\left(X^{2}\right)$ \\
\hline Pregnancies total & $43.7 \%(14 / 32)$ & $25.7 \%(9 / 35)$ & $<0.05(\mathrm{~S})$ \\
\hline Miscarriages; \% (n) & $0 \%(0)$ & $0 \%(0)$ & - \\
\hline Multiple; \% (n) & $7.1 \%(1 / 14)$ & $0 \%(0 / 9)$ & - \\
\hline Ectopic pregnancies; \% (n) & $7.1 \%(1 / 14)$ & $11.1 \%(1 / 9)$ & 0.741 \\
\hline Live births; \% (n) & $0 \%(0 / 14)$ & $0 \%(0 / 8)$ & - \\
\hline Singletons; \% (n) & $85.7 \%(12 / 14)$ & $100 \%(8 / 8)$ & \\
\hline
\end{tabular}

CC: Clomiphene citrate, hMG: Human menopausal gonadotropins, OHSS: Ovarian hyperstimulation syndrome, *Values are (mean \pm sd), NS: Not significant; $X^{2}$ : Chi square.

\section{DISCUSSION}

Although CC is a successful ovulation-inducing agent, the number of pregnancies achieved after ovulation induction with $\mathrm{CC}$ is much lower than expected..$^{22,25,26}$ The use of gonadotropins in ovulation induction is associated with increased risks of OHSS and multiple pregnancies and, therefore, intense monitoring of ovarian response is required. ${ }^{27-29}$ The sequential $\mathrm{CC}+\mathrm{hMG}$ treatment appears to be cost effective in ovulation induction leading to satisfactory pregnancy results. ${ }^{22,24}$ In present study there was no significant difference between the two studied groups regarding endometrial thickness $(8.3 \pm 2.1$ versus $9.7 \pm 2.8$, respectively), number of mature follicles on the day of hCG injection $(3.3 \pm 1.2$ versus $3.5 \pm 1.1$, respectively) and, but there was significant difference between the $\mathrm{CC}+\mathrm{hMG}$ group and $\mathrm{CC}$ group regarding the total dose of gonadotropins used in ovulation induction $(305 \pm 23.8$ versus $655 \pm 192$; total IU, respectively) $\mathrm{p}<0.05$.

But the pregnancy rate was significantly high in the $\mathrm{CC}+\mathrm{hMG}$ group compared to the CC group [14 (43.7\%) versus $9(25.7 \%)$, respectively] $(\mathrm{p}<0.05)$. There are no statistically significant differences between the two groups regarding age and body mass index (BMI). There were also no statistically significant differences between the two groups in terms of duration of infertility. Higher pregnancy rates have been reported following IUI compared to expectant management (51 versus 33\%, respectively). ${ }^{30}$ Another 412 infertile women with unexplained infertility were randomized to receive either $100 \mathrm{mg}$ of CC daily or $5 \mathrm{mg}$ of letrozole daily for 5 days, starting on day 3 of menses by Badawy et al. For ovulation induction in CC-resistant women with PCOS.

They found no statistically significant difference in pretreatment endometrial thickness or endometrial thickness at the time of hCG administration between the two groups. ${ }^{31}$ Study is consistent with earlier reports with regard to the lack of benefit of CC. ${ }^{32}$ It has now been recognized that aggressive ovarian stimulation can increase the pregnancy rate, but at the expense of increasing the likelihood of higher-order pregnancy, and that an increasing number of follicles does not increase the pregnancy rate but only leads to a higher risk of multiple pregnancies.

\section{CONCLUSION}

Women undergoing IUI, ovarian stimulation CC combined with hMG, significantly improved the pregnancy and live birth rates as compared to that of CC group. In women undergoing ovarian stimulation and IUI, there are no significant differences in pregnancy and live birth rates among the various stimulation protocols. This study is in concordance with this work and demonstrates that there is no significant difference in clinical outcomes between different in IUI cycles, BMI and infertility types, including the age, and the Swim-up sperm, Primary infertility and Secondary infertility. The $\mathrm{CC}+\mathrm{hMG}$ to COS-IUI cycles significantly increased pregnancy rates in study patients. Since this increase seems to be related to the number of follicles recruited, clinicians should balance this benefit against the risk of multiple gestation in IUI. 


\section{ACKNOWLEDGMENTS}

Authors would like to thank Obstetrics and Gynecology Department. This work was supported by the D. Y. Patil Fertility Centre, Navi Mumbai, Maharashtra, India.

Funding: No funding sources Conflict of interest: None declared

Ethical approval: The study was approved by the Institutional Ethics Committee

\section{REFERENCES}

1. Custers IM, Steures P, Hompes P, Flierman P, van Kasteren Y, van Dop PA, et al. Intrauterine insemination: how many cycles should we perform? Hum Reprod. 2008;23(4):885-8.

2. McClamrock HD, Jones HW, Adashi EY. Ovarian stimulation and intrauterine insemination at the quarter centennial: implications for the multiple births epidemic. Fertil Steril. 2012;97(4):802-9.

3. Group ECW. Intrauterine insemination. Hum Reprod Update. 2009;15(3):265-77.

4. Merviel P, Heraud MH, Grenier N, Lourdel E, Sanguinet P, Copin H. Predictive factors for pregnancy after intrauterine insemination (IUI): an analysis of 1038 cycles and a review of the literature. Fertil Steril. 2010;93(1):79-88.

5. Oehninger S. Place of intracytoplasmic sperm injection in management of male infertility. The Lancet. 2001;357(9274):2068-9.

6. Abdelkader AM, Yeh J. The potential use of intrauterine insemination as a basic option for infertility: a review for technology-limited medical settings. Obstet Gynecol Inter. 2009;584837:11.

7. Katzorke T, Kolodziej FB. Significance of insemination in the era of IVF and ICSI. Der Urologe-Ausgabe A. 2010;49(7):842-6.

8. Monraisin O, Chansel-Debordeaux L, Chiron A. Evaluation of intrauterine insemination practices: a 1-year prospective study in seven French assisted reproduction technology centers. Fertil Steril. 2016;105(6):1589-93.

9. The ESHRE Capri Workshop Group. Intrauterine insemination. Human Reprod Update. 2009; 15(3):265-77.

10. Campana A, Sakkas D, Stalberg A, Bianchi PG, Comte I, Pache T, et al. Intrauterine insemination: evaluation of the results according to the woman's age, sperm quality, total sperm count per insemination and life table analysis. Human Reprod. 1996;11(4):732-6.

11. Khalil MR, Rasmussen PE, Erb K, Laursen SB, Rex S, Wester gaard LG, Homologous intrauterine insemination. An evaluation of prognostic factors based on a review of 2473 cycles. Acta Obstetricia et Gynecol Scandina. 2001;1(80):74-81.

12. Kamath MS, Bhave PTK, Aleyamma TK, Nair R, Chandy A, Mangalaraj AM, Muthukumar K, et al. Predictive factors for pregnancy after intrauterine insemination: a prospective study of factors affecting outcome. J Human Reprod Sci. 2010;3(3):129-34.

13. Tijani HA, Bhattacharya S. The role of intrauterine insemination in male infertility. Human Fertil. 2010;4(13):226-32.

14. Souter I, Baltagi LM, Kuleta D, Meeker JD, Petrozza JC. Women, weight, and fertility: the effect of body mass index on the outcome of superovulation/intrauterine insemination cycles," Fertil Steril. 2011;95(3):1042-7.

15. Soria M, Pradillo G, García J, Ramón P, Castillo A, Jordana C, et al. Pregnancy predictors after intrauterine insemination: analysis of 3012 cycles in 1201 couples. J Reprod Infertil. 2012;13(3):158-66.

16. Dilbaz B, Ozkaya E, Inar MC. Predictors of total gonadotropin dose required for follicular growth in controlled ovarian stimulation with intrauterin insemination cycles in patients with unexplained infertility or male subfertility. Gynecol Obstet Reprod Med. 20011;1(17):28-33.

17. Ecochard R, Mathieu C, Royere D, Blache G, Rabilloud M, Czyba JC. A randomized prospective study comparing pregnancy rates after clomiphene citrate and human menopausal gonadotropin before intrauterine insemination. Fertil Steril. 2000;73(1):90-3.

18. Dankert T, Kremer JA, Cohlen BJ, Hamilton CJ, Pasker-de Jong PC, Straatman $\mathrm{H}$, et al. A randomized clinical trial of clomiphene citrate versus low dose recombinant FSH for ovarian hyperstimulation in intrauterine insemination cycles for unexplained and male subfertility. Hum Reprod. 2007;22(3):792-7.

19. Berker B, Kahraman K, Taskin S, Sukur YE, Sonmezer M, Atabekoglu CS. Recombinant FSH versus clomiphene citrate for ovarian stimulation in couples with unexplained infertility and male subfertility undergoing intrauterine insemination: a randomized trial. Arch Gynecol Obstet. 2011;284(6):1561-6.

20. Goverde AJ, McDonnell J, Vermeiden JP, Schats R, Rutten FF, Schoemaker J. Intrauterine insemination or in-vitro fertilization in idiopathic subfertility and male subfertility: a randomised trial and costeffectiveness analysis. Lancet. 2000;355(9197):13-8.

21. Honda T, Tsutsumi M, Komoda F, Tatsumi K. Acceptable pregnancy rate of unstimulated intrauterine insemination: a retrospective analysis of 17,830 cycles. Reprod Med Biol. 2015;14:27-32.

22. The Practice Committee of the American Society for Reproductive Medicine (ASRM). Use of clomiphene citrate in women. Fertil Steril. 2006;86(4):S187S193.

23. Akbary-Asbagh F, Heidar Z, Frozan-Fard F, Nouri $\mathrm{K}$, Azmodeh O, Ghasemynejad A, et al. Evaluation of letrozole therapeutic effect in infertile women. Medica Iranica. 2007;45(3):199-203.

24. Ganesh A, Goswami SK, Chattopadhya R, Chaudhury K, Chakravarty B. Comparison of letrozole with continuous gonadotrophins and 
clomiphene-gonadotropic combination for ovulation induction in 1387 PCOS women after CC failure: a randomized prospective clinical trial. J Assist Reprod Genet. 2009;26(1):19-24.

25. Abu Hashim H. Clomiphene citrate alternatives for the initial management of polycystic ovary syndrome: an evidence-based approach. Arch Gynecol Obstet. 2012;285(6):1737-45.

26. Homburg R, Pap H, Brandes M, Huirne J, Hompes $\mathrm{P}$, Lambalk CB. Endometrial biopsy during induction of ovulation with clomiphene citrate in polycystic ovary syndrome. Gynecol Endocrinol. 2006;22(9):506-10.

27. Baysoy A, Serdaroglu H, Jamal H, Karatekeli E, Ozornek H, Attar E. Letrozole versus human menopausal gonadotrophin in women undergoing intrauterine insemination. Reprod Biomed Online. 2006;13(2):208-12.

28. Palomba S, Falbo A, Zullo F. Management strategies for ovulation induction in women with polycystic ovary syndrome and known clomiphene citrate resistance. Curr Opin Obstet Gynecol. 2009;21(6):465-73.

29. Thessaloniki ESHRE/ASRM-Sponsored PCOS Consensus Workshop Group. Consensus on infertility treatment related to polycystic ovary syndrome. Fertil Steril. 2008;89(3):505-22.
30. Steures P, van der Steeg JW, Hompes PG, Bossuyt PM, Habbema JD, Eijkemans MJ, et al. Effectiveness of intrauterine insemination in subfertile couples with an isolated cervical factor: a randomized clinical trial. Fertil Steril. 2007;88(6):1692-6.

31. Badawy A, Mosbah A, Shady M. Anastrozole or letrozole for ovulation induction in clomipheneresistant women with polycystic ovarian syndrome: a prospective randomized trial. Fertil Steril. 2008;89(5):1209-12.

32. Gomez R, Schorsch M, Steetskamp J, Hahn T, Heidner K, Seufert R, et al. The effect of ovarian stimulation on the outcome of intrauterine insemination. Arch Gynecol Obstet. 2014;289(1):181-5.

Cite this article as: Singh A, Palshetkar R, Singh N, Rege A. Comparison of pregnancy outcome between clomiphene citrate and sequential clomiphene citrate+human menopausal gonadotropin in intrauterine insemination. Int J Reprod Contracept Obstet Gynecol 2020;9:3302-7. 